\title{
ENSINO DE GEOGRAFIA E EDUCAÇÃO AMBIENTAL MEDIADO PELO O USO DE TEXTUALIDADES IMAGÉTICAS (ORBITAIS) EXTRAÍDAS DO GOOGLE EARTH
}

\author{
Geography and environmental education mediated by the use of extracted \\ imagetic textuals from google earth
}
Geografía y educación medioambiental educación mediada por el uso de textualidades imágticas extractas de google earth

Luiz Martins Junior*
Marcos Vinicius Campelo Junior
Marcia Vidal Candido Frozza

\section{Resumo:}

Neste artigo são analisadas a relevância e potencialidades da sequência didática (SD) com foco específico na utilização de textualidades imagéticas do Google Earth e temática Educação Ambiental adotada em uma escola pública de Campo Grande (MS). O planejamento, construção e aplicação da SD tem caráter qualitativo, com delineamento empírico experimental. As imagens selecionadas mostram o lixão da cidade e a ocupação progressiva das áreas habitadas. Por meio delas, buscou-se identificar a aprendizagem com mudança conceitual e a superação de situações-limite dos estudantes no enfrentamento de problemas socioambientais encontrados em seu cotidiano. Dentre os resultados, foi possível constatar que a SD contribuiu não só para a construção e profusão dos conceitos geográficos, mas também se revelou como potencial ferramenta didático-pedagógica na Educação Ambiental.

Palavras-chave: Ensino de Geografia. Educação ambiental. Textualidades imagéticas.

\begin{abstract}
:
This article analyzes the relevance and potential of the didactic sequence (SD) with a specific focus on the use of Google Earth imagery textual and Environmental Education theme adopted in a public school in Campo Grande (MS). The planning, construction and application of DS has a qualitative character, with experimental empirical design. The selected images show the city's dump and the progressive occupation of inhabited areas. Through them, we sought to identify learning with conceptual change and overcoming students' limit situations when facing socio-environmental problems encountered in their daily lives. Among the results, it was found that DS contributed not only to the construction and profusion of geographical concepts, but also revealed as a
\end{abstract}


potential didactic-pedagogical tool in Environmental Education.

Keywords: Geography teaching. Environmental education. Imagetic textualities.

Resumen:

Este artículo analiza la relevancia y el potencial de la secuencia didáctica (SD) con un enfoque específico en el uso de imágenes de Google Earth textuales y el tema de Educación Ambiental adoptado en una escuela pública en Campo Grande (MS). La planificación, construcción y aplicación de DS tiene un carácter cualitativo, con diseño empírico experimental. Las imágenes seleccionadas muestran el basurero de la ciudad y la ocupación progresiva de las áreas habitadas. A través de ellos, buscamos identificar el aprendizaje con un cambio conceptual y superar las situaciones límite de los estudiantes al enfrentar problemas sociales y ambientales que se encuentran en su vida diaria. Entre los resultados, se encontró que DS contribuyó no solo a la construcción y profusión de conceptos geográficos, sino que también se reveló como una potencial herramienta didáctico-pedagógica en Educación Ambiental.

Palabras clave: Enseñanza de geografía. Educación ambiental. Textualidades imaginarias.

\section{Introdução}

Este texto é resultado da pesquisa de Mestrado realizada no Programa de Ensino de Ciências da Universidade Federal de Mato Grosso do Sul, em 2015, que analisou e refletiu sobre as potencialidades do uso das textualidades imagéticas (orbitais) extraídas da ferramenta Google Earth no processo de ensino e aprendizagem. Para trabalhar a temática Educação Ambiental (lixo urbano, ilhas de calor, inversão térmica, poluição das águas, erosão, chuva ácida, enchentes, poluição visual e poluição sonora), utilizou-se a proposta de sequência didática (SD) na perspetiva dialógica como um recurso de mediação e possibilidade para o fazer pedagógico.

Em virtude do panorama atual, de crise da civilização, emerge a necessidade de transformações para sobrepujar as injustiças ambientais e sociais, a apropriação da natureza e da própria humanidade (LEFF, 2006). Nesse cenário, a Educação Ambiental (EA) assume papel preponderante no enfrentamento dessa crise socioambiental, com o compromisso de mudança de valores, atitudes, sentimentos e quebra de paradigmas. Portanto, conforme enfatizada por Loureiro (2012), trata-se de uma EA crítica, que se integra em sua lógica de ação e reflexão para transformação das relações de seres humanos entre si e entre esses e o meio ambiente que afasta propostas de EA de caráter moralista, reducionista, ingênuo, sem fundamentação teórica consistente e descomprometida com transformações necessárias.

A temática ambiental, em toda sua complexidade, tem sido o mote de debates e estudos nas últimas décadas e sua importância vem, a cada dia, ganhando destaque. Os problemas ambientais, a exemplo disso, têm se tornado um convite a novas reflexões, na tentativa de encontrar e propor soluções sustentáveis por parte de diversos profissionais. Nessa perspectiva, entende-se que a escola, como ambiente formal dos processos de ensino e de aprendizagem, deve ser campo de discussões a respeito de questões 
importantes dos contextos socioambientais, questões que professores, em conjunto com toda comunidade escolar, precisam tornar realidade nos processos pedagógicos a partir do próprio ambiente em que vivem os estudantes: da escala local para a global.

As discussões e práticas de EA necessitam ser impulsionadas e expandidas no espaço da escola e em seu entorno, sobretudo para proporcionar aos estudantes e às comunidades a possibilidade de seus papéis ativos, para além dos muros da escola, posto que a EA representa um relevante instrumento para provocar a percepção necessária na integração entre as pessoas e destas com os espaços que se inserem, permitindo a formação de cidadãos numa nova relação com o meio ambiente (GUIMARÃES, 2011). Por conseguinte, em meio a discussões sobre a EA, entende-se que o professor da disciplina de Geografia da Educação Básica pode corroborar para a percepção dos problemas ambientais, bem como contribuir para a autonomia do estudante como sujeito consciente nas relações socioambientais no mundo vivido, pois que o professor, dentro das problemáticas enfrentadas no processo de ensino e aprendizagem, é elemento fundamental na inserção da EA na escola (GUERRA, 2010).

Nesse contexto, a Geografia escolar possibilita trabalhar as questões ambientais em movimento contrário ao das degradações socioambientais, partindo da realidade da comunidade escolar, de forma coletiva e interdisciplinar, propondo agir e pensar diante das complexidades da sociedade contemporânea e da crise que vem se estabelecendo em níveis locais e globais (LEFF, 2006).

Coerente da importância de estudar a temática Educação Ambiental no ensino de Geografia, este texto está organizado da seguinte forma: em um primeiro momento, trazemos as considerações sobre o ensino de Geografia e as tecnologias digitais. Acompanhada dessa escrita, situamos o desenho metodológico, destacando o contexto da pesquisa e o perfil dos participantes seguido dos resultados do estudo feito com os estudantes envolvidos na prática de ensino. Finalizando, apresentamos algumas considerações, destacando as potencialidades que tanto a ferramenta Google Earth proporciona para compreender a temática Educação Ambiental quanto o uso da Sequência didática como uma possibilidade para trabalhar o ensino de Geografia.

\section{A geografia escolar e as tecnologias digitais}

O ensino de todas as ciências se depara com vários produtos da indústria cultural (charges, músicas, filmes, fotografias, mapas temáticos, maquetes e outros), mormente em virtude das tecnologias digitais que trazem informações por meios digitais - fato inerente às mudanças contemporâneas na sociedade do "meio técnico-científico-informacional" (SANTOS, 2002).

A apropriação desses recursos, bem como a assimilação das novas linguagens, exigem do professor, e da escola, interesse, preparo, formação, disponibilidade de recursos materiais e uma avaliação contínua do uso desses meios tecnológicos como ferramentas pedagógicas, pois o emprego das 
informações, com uso dessa ferramentas, que emergem em grande velocidade e quantidade, nem sempre é sistematizado, o que pode reduzir a potencialidade e a construção do conhecimento em sala de aula. O papel do professor, como orientador/mediador, é, portanto, complexo e exigente. Conforme ressaltado por Moran (2000, p. 348), "[...] educar é um processo cada vez mais complexo porque a sociedade também evolui rapidamente, exige mais competências, torna-se mais complexa também. Em geral temos avançado em descobrir novas formas de ensinar e de aprender".

As escolas enfrentam grandes desafios no que diz respeito ao advento das tecnologias em sala de aula, porque as novidades tecnológicas que surgem constantemente, muitas vezes, tangem a realidade vivida dos estudantes, logo, o professor deve estar ciente, atualizado e preparado para adequar sua prática pedagógica para os novos cenários que o cerca. Nesse sentido, há uma crise paradigmática na educação que está induzindo mudanças profundas na maneira do pensar pedagógico.

Ensinar com a presença das "tecnologias digitais" é um desafio constante quando se trata da sala de aula. $E$ as tecnologias de informação e comunicação, cada vez mais, fazem parte do contexto escolar, uma vez que existem propostas concretas de mudanças já presentes em muitas das escolas e universidades: educação à distância, classe conectada à internet, cada estudante com um notebook ou tablet, pesquisas rápidas com smartphones durante a aula, aulas-show disponíveis em websites de stream, entre outras. Observa-se, desse modo, que tecnologias digitais estão trazendo novos desafios pedagógicos às universidades e escolas.

No ensino de Geografia, recursos, como programas de computador e a internet, podem ser utilizados pelos professores e pelos estudantes de forma didático-pedagógica na (des)construção do conhecimento. Deve-se destacar, ainda, a socialização do conhecimento geográfico com o auxílio dos recursos tecnológicos disponíveis. Segundo os PCN:

\begin{abstract}
Pelo ensino de Geografia é possível que os alunos compreendam os processos e produção cultural e conheçam a utilização das tecnologias da comunicação e informação. Além disso, as tecnologias da informação podem ser utilizadas como recurso didático para ensinar os conteúdos específicos desta área (BRASIL, 1998, p. 141).
\end{abstract}

Verifica-se ser a globalização um processo sem retorno, em outras palavras, um fenômeno de cientificização, tecnicização e informatização irreversível para todos na construção histórica da humanidade e que é evidenciado na transformação dialética do espaço geográfico. Desse modo, o estudante não pode ser abstraído de entender tal momento. Segundo Pontuschka, Paganelli e Cacete (2009), a escola, com reflexão e visão crítica, deve apropriar-se das várias linguagens e meios de comunicação para ensinar a decodificação, a análise, a interpretação e o uso de dados e informações, a fim de contribuir com o desenvolvimento do estudante no que tange às competências e habilidades de assimilar e conviver com as tecnologias, que permitem novas formas de aprender, as quais devem, igualmente, se consolidar com reflexão e visão crítica. 
No ensino de Geografia, a utilização de softwares para o processamento de informações espaciais, dados estatísticos e imagens digitais como recurso didático pode subsidiar a interpretação da realidade socioambiental. Os avanços da ciência e das inovações tecnológicas têm sido consideráveis e exigem conhecimentos especializados nas diversas áreas e, na disciplina geográfica, permitem compreender melhor as transformações do espaço geográfico, o que, para o estudante, contribui no desenvolvimento da capacidade de interpretação e abstração dos fenômenos espaciais. As ferramentas tecnológicas são indispensáveis na cartografia digital em diversas temáticas, com significativas possibilidades de aprendizagem e de pesquisa, mesmo na Educação Básica. No ensino, constituem elementos didáticos que podem contribuir para a realização de atividades dinâmicas, diversificadas e atrativas nas salas de aula.

Em consonância com a proposta da pesquisa, cujos resultados são aqui apresentados, observa-se que, apesar do fato das imagens orbitais terem sido criadas e utilizadas para fins militares inicialmente, vem crescendo nas aulas de Geografia o uso dessas representações/recursos, com eminente potencial para diversos objetivos de aprendizagem. A utilização desse tipo de textualidade imagética, na maioria das vezes, se volta para estudos ambientais (desmatamento, tipos de vegetação, mancha urbana, entre outras temáticas), entretanto, para a construção de práticas pedagógicas com conceitos da Geografia na Educação Básica, ainda não se identifica ampla utilização que facilite os aprendizados conceituais esperados. Junto a isso, é comum relatos de professores que apontam dificuldades no acesso às tecnologias nas escolas, como no caso da disponibilidade de aparatos tecnológicos (computadores, projetores, reprodutores de som, internet) e de estrutura física, principalmente nas escolas públicas das periferias do nosso país. Há, além disso, dificuldade e aversão de alguns professores em trabalhar com as tecnologias, preferindo continuamente as tradicionais aulas expositivas.

Por outro lado, a utilização excessiva das tecnologias como ferramenta pode se tornar um "vício didático" que não levaria à aprendizagem, pois, no caso das textualidades imagéticas, assumiriam caráter apenas ilustrativo. Conforme ressalta Silva Filho (2008, p. 63), "[...] ao contrário de que muitos pensam, não são as imagens de satélite que deixam as aulas de Geografia mais atrativas ou interessantes, capazes de motivar o aluno, e sim o uso coerente que o professor faz desse recurso em suas aulas".

As imagens orbitais, como linguagem visual no ensino de Geografia, permitem a identificação de elementos da paisagem e mesmo a possibilidade de acompanhamento da dinâmica espaço-temporal do espaço geográfico, tais como desflorestamentos, monitoramento de queimadas, de mananciais hídricos e expansão urbana, como é o caso desta pesquisa. A leitura das imagens mostra a relevância da "alfabetização cartográfica" (SIMIELLI, 2009), já que ler mapas requer um processo de codificação e decodificação, com a possibilidade descritiva do espaço geográfico em suas características qualitativas e quantitativas. As imagens orbitais permitem, então, levar o estudante a perceber as diferentes escalas e a analisar fenômenos de realidades distantes e nunca presenciadas. 


\section{Metodologia}

A pesquisa desenvolveu-se de forma qualitativa, com delineamento empírico experimental. Segundo Gil (2008), há pesquisas que, embora não apresentem distribuição eventual dos sujeitos nem grupos de controle, são desenvolvidas com bastante rigor metodológico e aproximam-se das pesquisas experimentais.

Nessa direção, para a experimentação da pesquisa com as imagens orbitais na SD, foi escolhido o Google Earth como ferramenta para percepção e análise dos problemas socioambientais. A ferramenta foi projetada como geradora de imagens orbitais e mapas, o que possibilita a identificação da paisagem e seus elementos. As imagens orbitais são arquivos imagéticos concebidos pela tecnologia de sensoriamento remoto, com base em satélites artificiais que estão em órbita do planeta Terra.

$\mathrm{Na}$ experiência pedagógica participaram 72 estudantes, com idades entre 14 e 17 anos, de duas turmas do $2^{\circ}$ ano do Ensino Médio da Escola Estadual Professor Severino de Queiroz, no bairro Monte Castelo, localização central da cidade de Campo Grande, Mato Grosso do Sul. A pesquisa foi realizada durante os meses de julho, agosto e setembro de 2015.

\section{Etapas da pesquisa}

Iniciamos o processo por meio do contato com a coordenadora pedagógica da referida escola, que analisou nosso projeto e nos apresentou ao professor regente de Geografia, sendo prontamente solícito a participar da pesquisa. Tanto a escola quanto professor e estudantes contavam com acesso a aparatos tecnológicos na escola e em suas residências. Confirmamos no conteúdo programático do $2^{\circ}$ ano do Ensino Médio para o segundo semestre a possibilidade de trabalhar a Educação Ambiental com o conteúdo "Problemas ambientais urbanos", previsto no plano de ensino do professor, atendendo ao disposto no Referencial Curricular da Rede Estadual de Ensino de Mato Grosso do Sul. No mesmo encontro foram definidos dia e horário para o primeiro contato com os estudantes (Turmas A e B do turno matutino).

$\mathrm{Na}$ construção da Sequência Didática (SD), três passos (planejamento, aplicação e avaliação) nortearam a intervenção reflexiva que se desenrolou em sete etapas:

A primeira etapa consistiu no encontro com os estudantes para definir o tema/conceito a ser abordado e a explanação sobre os problemas relacionados: lixo urbano, ilhas de calor, inversão térmica, poluição das águas, erosão, chuva ácida, enchentes, poluição visual e poluição sonora

A segunda etapa foi de avaliação diagnóstica inicial, para verificar indícios e percepções antecedentes sobre o conteúdo.

$\mathrm{Na}$ terceira etapa, propusemos aos educandos uma pesquisa, individual ou coletiva, sobre o conceito de lixo para provocar uma situação conflitante de ideias entre os conhecimentos de senso comum e científico para uma discussão coletiva comparativa dos conceitos de lixo e resíduos sólidos.

A quarta etapa foi para assistir à animação Consciente coletivo (com 2 minutos de duração) para uma discussão conjunta a respeito dos problemas de causa-efeito e a história do lixo no universo social, sua relação histórica com a 
humanidade e para pensar possibilidades de solução inicial para o problema. Nesse momento foi usado o Data show com slides para ilustrar algumas informações sobre os resíduos sólidos.

$\mathrm{Na}$ quinta etapa, após breve introdução do pesquisador ao sensoriamento remoto para melhor entendimento da tecnologia a ser utilizada, foi proposto exercício em duplas, na sala de informática, analisar e extrair imagens orbitais do programa de computador Google Earth que versavam sobre macroproblemas socioambientais locais e de outras localidades. O objetivo foi o de compreender a funcionalidade e importância do sensoriamento remoto. Utilizar o programa Google Earth para analisar imagens orbitais dos problemas socioambientais.

Na sexta etapa, utilizamos uma notícia de um canal de comunicação local a respeito do tema/conceito trabalhado nas aulas para ilustrar e auxiliar os estudantes a reconhecerem o problema dos resíduos sólidos. Esse procedimento também serviu para que a comunidade local entendesse a necessidade de mudanças atitudinais por parte de toda a população.

A sétima etapa consistiu na avaliação diagnóstica final (confrontada com a avaliação inicial), para averiguar se houve aprendizagem por meio da SD.

A análise da aplicação da SD se deu por meio do confronto entre a avaliação diagnóstica inicial e a avaliação diagnóstica final, a considerar todo o processo, a fim de que melhor fosse constatado o que se consolidou enquanto aprendizado, bem como a eficácia da própria estratégia pedagógica. É interessante ressaltar que, ao longo das aplicações da atividade proposta, o uso das imagens orbitais, por meio da ferramenta Google Earth, possibilitou trabalhar na SD temáticas sobre os problemas ambientais urbanos, ocorrendo uma análise multi-temporal das imagens orbitais do lixão de Campo Grande, nos anos de 2002 a 2014, havendo comparação com o lixão de outros estados, provocando, assim, um olhar crítico para o espaço em suas dimensões social, política, econômica e ambiental. Outro foco pertinente foi a possibilidade em trabalhar a Educação Ambiental no sentido de instigar os estudantes a pensarem medidas mitigadoras para as problemáticas relacionadas ao consumo, acúmulo, descarte, coleta, reciclagem e/ou reutilização de lixo (resíduos sólidos).

\section{Resultados e discussões}

Diante dos resultados obtidos ao longo das atividades aplicadas, pode-se dividir em Avaliações Diagnósticas Iniciais (ADI) e Avaliações Diagnósticas Finais (ADF), com a adição das observações em todo o processo e a análise do relato do professor regente. Nesse sentido, considera-se que a análise dos dados é cíclica e inicia-se no momento da própria coleta, numa comunicação entre as etapas (TESHE, 1990).

A leitura dos dados foi separada em eixos: No eixo 1, situa-se a enunciação conceitual dos estudantes sobre os resíduos sólidos e sua origem. $\mathrm{O}$ eixo 2 evidencia a percepção dos estudantes sobre resíduos sólidos e problemáticas vivenciadas na própria realidade. O eixo 3 identifica a opinião e as sugestões dos estudantes sobre a estratégia utilizada durante o processo de ensino e 


\section{aprendizagem.}

As atividades, com o escopo de revelar a percepção conceitual a respeito das problemáticas e senso crítico sobre os resíduos sólidos por parte dos estudantes, apontou que a SD, de proposta dialógica, com o uso de imagens orbitais, contribuiu na aprendizagem de conceitos da Geografia e na Educação Ambiental dos estudantes participantes desta pesquisa. No entanto, neste artigo constam somente as análises que representam reflexões pertinentes acerca do efeito da SD experimentada.

Os estudantes, quando questionados sobre seus entendimentos sobre 'lixo', responderam em sua ADI (Avaliação Diagnóstica Inicial) que o lixo era algo sem uso, portanto deveria ser descartado. Em um segundo momento, na ADF (Avaliação Diagnóstica Final), questionados sobre o mesmo conceito, apresentaram respostas mais elaboradas, focando que 0 lixo pode ser reaproveitado quando há um destino correto.

Em análise mais precisa desses resultados, no início da sequência Didática os estudantes não utilizavam palavras como 'resíduo' ou 'objeto'. Entendiam que descartar era o procedimento/destino adequado para o 'lixo'. Assim, pressupõe-se que não manifestavam conhecimento esclarecido de outras formas de utilização do resíduo, o que forneceu aos pesquisadores um dado importante para pensar a SD, qual seja, o esclarecimento de conceitos a partir de exemplos da própria realidade pode conduzir a formação de um pensamento mais consciente.

Desse modo, reflexões importantes surgiram por parte dos estudantes na afirmativa "a grande formação do lixo é devida ao nosso consumismo excessivo, que gera o lixo acumulado e cria problemas a todos". Os exemplos citados apontam para produtos industrializados, produtos orgânicos que são descartados no lixo comum, provocando apodrecimento. Pode-se notar que as respostas apresentadas mostram uma diferença considerável no nível de desenvolvimento dos estudantes, aspecto que foi levado em consideração no planejamento e aplicação da SD.

Nesse caminho, a ADI apontou para resíduos descartados que acabam por prejudicar tanto o meio ambiente quanto as pessoas se não forem tratados da maneira adequada, o que pode resultar no aproveitamento de muitos materiais para compor outros produtos, citando-se como exemplo o plástico, o vidro, os metais e o papel.

Nas avaliações iniciais, 57 estudantes demonstraram dificuldade em conceituar lixo e explicar sua origem. Muitos responderam que "Lixo é sujeira" ou "Aquilo que não presta mais", mostrando conhecimentos do senso comum, sem muito domínio de vocabulário e conceitos mais elaborados. As respostas revelam, ainda, diversidade nos níveis de conhecimento prévio dos estudantes. No confronto das questões do eixo 1, nas avaliações iniciais e finais, percebeuse que houve progresso em relação ao conhecimento, pois a maior parcela dos estudantes, de aproximadamente $90 \%$, conseguiu estabelecer relações entre os novos conteúdos e os conhecimentos anteriores, demonstrando conhecimentos construídos em relação aos conceitos. 
No eixo 2 foram aplicadas questões relativas à destinação correta do lixo e sua causa-efeito quando descartado de maneira incorreta. Em suas respostas, os estudantes apresentam conceitos atitudinais (ZABALA, 1998) trabalhados nas atividades, descrevendo inicialmente situações de tentativa de mudança comportamental de sua realidade. Entende-se que são tendências ou predisposições dos estudantes para atuarem com reflexão diante de situações comuns que envolvem a problemática relacionada aos resíduos sólidos, provavelmente devido ao fato da atual organização do espaço, de uma configuração em vigência comum da divisão e organização do trabalho, produzindo, desse modo, comportamentos que levam ao consumo e orientam a vida cotidiana para esse fim. Segundo Santos (2014), é no plano do lugar que é "[...] possível compreender a racionalidade homogeneizante inerente ao processo de acumulação, que não se realiza apenas a partir da produção de objetos e mercadorias" "(p. 11).

Constata-se, ainda, que as imagens orbitais obtidas por meio do Google Earth (figuras 1, 2, 3, 4, 5 e 6) tiveram papel importante, revelando ao estudante, por meio de uma análise multi-temporal das imagens, a rápida expansão urbana e sua aproximação ao "lixão" da cidade, hoje, aterro sanitário. Isso desencadeou discussões acerca da origem dos resíduos desde quando eram matéria-prima.

Figuras 1, 2, 3, 4, 5 e 6. Localização do lixão da cidade - Campo Grande/MS.
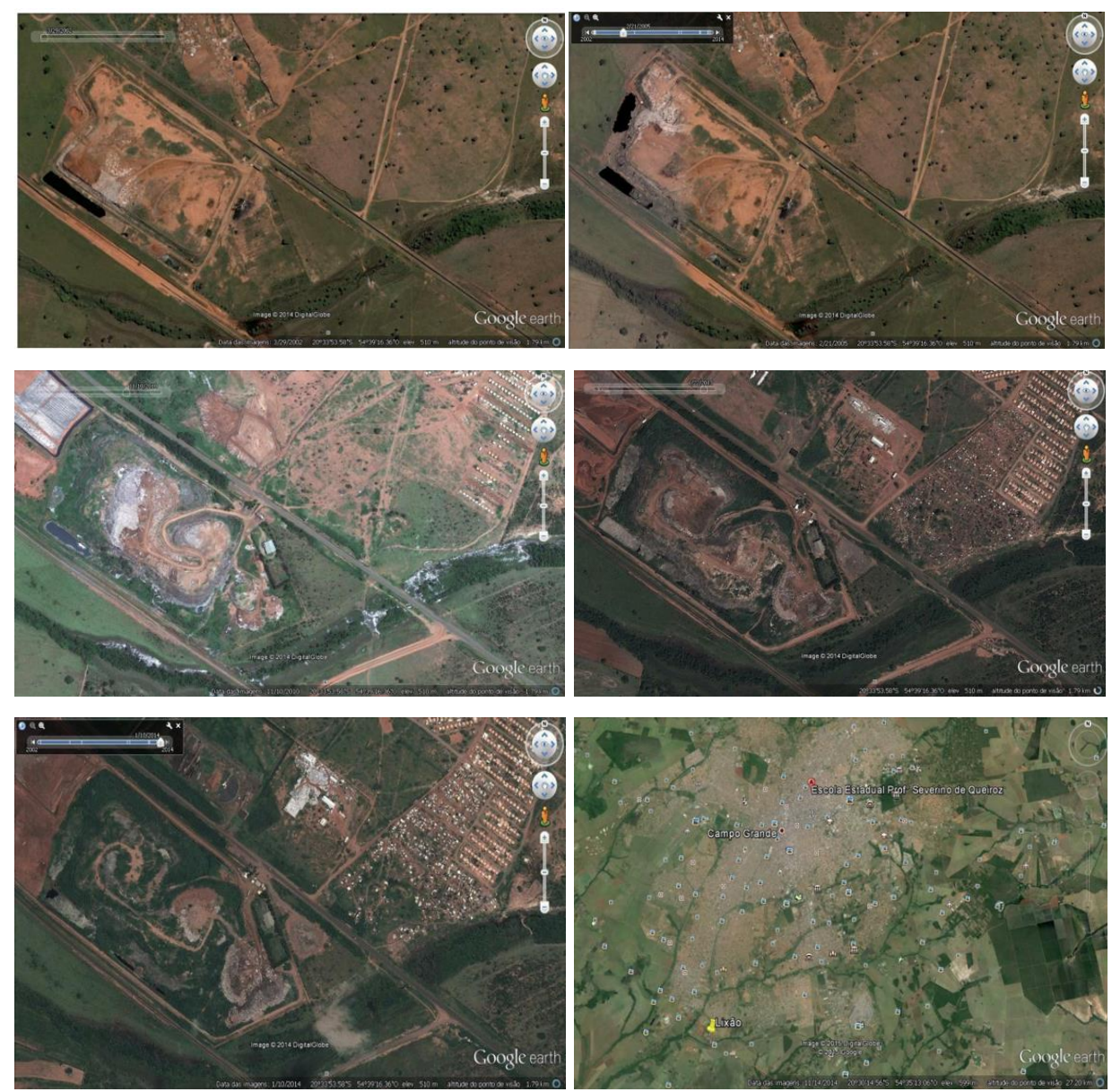

Fonte: autores: 2015.

Para0nde!?, Porto Alegre, v.13, n.1, p. 97-110, 2020. http://seer.ufrgs.br/paraonde 
Com relação ao eixo 3, as questões propostas tiveram como propósito considerar as respostas dos estudantes como possibilidades a serem levadas em conta em futuros planejamentos e avaliações quanto às questões ambientais no sentido de sanar dúvidas ou promover aulas que atendam às expectativas desses sujeitos. Nesse ponto,

As respostas e opiniões mostram como eles [os estudantes] estão reagindo à atuação do professor, às dificuldades que encontram na assimilação dos conhecimentos. Servem, também, para diagnosticar as causas que dão origem a essas dificuldades. (LIBÂNEO, 1994, p. 250).

A partir desse pensamento, entende-se que conhecer os anseios, dificuldades, expectativas, opiniões e sugestões dos estudantes deve ser uma prática comum, tanto na construção do planejamento, como na avaliação das aulas ocorridas. Afinal, a relação de reciprocidade democrática, da dialogicidade entre professores e estudantes na construção do conhecimento torna-se eficaz no pensar procedimentos para a sala de aula. Nesse sentido, os questionamentos abarcaram a opinião dos estudantes acerca do tema e das atividades aplicadas.

$\mathrm{Na}$ comparação das avaliações inicial e final da etapa sete, percebe-se que houve reconhecimento e assentimento por parte dos estudantes sobre os processos de ensino e de aprendizagem, já que expressam que a aprendizagem aconteceu. Nesse sentido, identificou-se que a participação dos estudantes e o respeito às suas opiniões foram primordiais no planejamento das atividades e na construção do conhecimento. Afinal, quando permanecem o diálogo, a compreensão, o respeito mútuo e a afetividade, existe interação e, por conseguinte, ampliação da aprendizagem.

\section{Análise do relato do professor regente}

O relato do professor que acompanhou as práticas pedagógicas foi importante, visto que se trata do olhar de quem convive com os estudantes e pode colaborar para que a percepção das dificuldades, facilidades, progressos, mudanças comportamentais e aprendizagem entre os estudantes seja mais consistente. No início do relato, o professor regente expôs sua surpresa ao perceber que um grande número dos estudantes apresentou interesse e curiosidade pela discussão desde o primeiro contato com a pesquisa. Salientou, ainda, que a forma diferenciada como foi abordado o tema e as problematizações chamou sua atenção. Nessa enunciação do professor, percebe-se, de modo latente, o reconhecimento de que a metodologia utilizada pode ter sido primordial, a fim de provocar a curiosidade dos estudantes para o tema durante as aulas, que já era dificuldade levantada pelo próprio, assim que ocorreu o primeiro contato para tratar sobre a proposta da pesquisa.

O professor reconhece que houve um momento conflitante importante na aceitação do novo conceito - resíduos sólidos -, que gerou intensa discussão entre os estudantes, mas que foi entendida como parte do processo da aprendizagem, pois logo muitos deles começaram a utilizar o novo conceito em suas falas, como foi observado durante as conversas entre os estudantes e 
deles com o professor. Este reconheceu a dedicação dos estudantes em encontrar alternativas para o problema dos resíduos sólidos - momento que gerou debates diante das possibilidades das propostas expostas, o que se entende como relevante para mudanças posturais no cotidiano.

O professor refere-se ao uso das imagens orbitais na SD como positivas e importantes durante as aulas. Com essa afirmação, pode-se inferir que as considera adequadas, bem exploradas, elucidativas e instigantes, o que prova a relevância das imagens na SD, visto que o professor levantou a questão da falta de participação dos estudantes em suas aulas. Sobre as imagens orbitais, na continuidade de seu relato, ele deixa claro a mudança de percepção e preocupação dos estudantes quando reconhecem que a problemática dos resíduos sólidos continua em outro espaço, longe de suas casas, mas que, ainda assim, afeta seu cotidiano. Portanto, entende-se que a atividade multiescalar com as imagens foi decisiva para reconhecer a relação entre espaços distantes, e que os problemas socioambientais em sua concretude são fruto da relação deles, estudantes, com o espaço geográfico.

As possibilidades de utilização do aplicativo Google Earth nas aulas de Geografia, a facilidade de trabalho com as ferramentas e o fato de se tratar de um programa gratuito chamaram a atenção do professor. O relato foi finalizado com a afirmação de que a SD aplicada contribuiu na aprendizagem. No entanto, o professor faz uma crítica ao tempo necessário para serem trabalhados os conteúdos, levando os pesquisadores a inferir que a real crítica seja em relação à cobrança de rapidez, para trabalhar o maior número de conteúdos durante o ano letivo. Com isso, pode-se caracterizar a configuração de um sistema educacional como 'conteudista', muito comum na educação baseada na pedagogia tradicional em diversas escolas.

Visivelmente, o comportamento dos estudantes se alterava durante o período de acompanhamento, o que revelava reclamações, inquietações e não colaboração na finalização das atividades. Muitas dessas, reconhece-se o motivo devido ao desconforto térmico, agravado pela infraestrutura do prédio da escola e o número elevado de estudantes por sala (cerca de 35), o que não privilegiava a circulação de ar no recinto, aumentando ainda mais a temperatura e dificultando a concentração. A atenção é um pré-requisito para o funcionamento de processos cognitivos mais complexos (CAMPOS; SANTACANA; NEBOT, 2008). Desse modo, em tais momentos de agravo nas predisposição para a aprendizagem, exigiu-se dos pesquisadores compreensão e tranquilidade para a aplicação das atividades. Conclui-se, porém, que apesar desse desafio, não conhecido durante o planejamento inicial, as circunstâncias não comprometeram os resultados da pesquisa.

\section{Considerações finais}

A pesquisa corrobora de modo a confirmar que o intercâmbio entre o modelo de aula tradicional, expositivo, e o modelo de aula com maior interação entre professor e estudantes, juntamente com a utilização de ferramentas 
tecnológicas, como as imagens orbitais do ferramentas Google Earth, podem contribuir na aprendizagem dos saberes da Geografia escolar, em especial, sobre o tema Educação Ambiental. Fato que pôde ser comprovado com os resultados das avaliações diagnósticas iniciais e finais, uma vez que demonstraram avanços conceituais, atitudinais e de tentativa de mudança comportamental dos estudantes após a aplicação da SD.

É importante ressaltar que a escolha de tema relacionado ao 'lixo', pelos estudantes, é muito comum, pois é algo visível, próximo, mas não adequadamente discutido. Assim, é sempre muito abordado quando se quer inserir a EA no processo de ensino como tema transversal. Porém, para que seja considerada uma EA crítica, é imprescindível que seja o tema que envolve resíduos sólidos abordado de maneira a associar com: o consumo, a saúde, e os estilos de vida, por exemplo, além de, consequentemente, com alguma especificidade do momento escolar.

Como as imagens demonstram, claramente, que a urbanidade vai, paulatinamente, aproximando a concentração das habitações com o "lixão", reflete-se que há falta do planejamento da expansão urbana, também tema do ensino de Geografia. Em vista disso, todavia para além da especificidade temática relacionada à pesquisa, contata-se que as imagens orbitais são uma saída para a impossibilidade do trabalho de campo com os estudantes, já que as escolas públicas nem sempre dispõem de recursos para transporte até o local de estudo pretendido. Além disso, as imagens expõem informações que permitem gerar conhecimento que atende a procura de soluções para problemas concretos.

Diante do que foi constatado, pode-se afirmar que o uso de imagens orbitais, na SD aplicada nas aulas de Geografia como proposta de Ensino de Geografia e EA, permitiu fazer conexões relevantes com os conteúdos, constituindo um valioso recurso pedagógico para o desenvolvimento da percepção, análise e criticidade, tendo, ainda, a capacidade de auxiliar na superação de problemáticas oriundas do cotidiano dos estudantes. Além do mais, do ponto de vista cartográfico, as imagens orbitais permitiram analisar diversas mudanças ocorridas na região, como a expansão do lixão, a alternância da vegetação dentro de seus limites, o aumento e diminuição da quantidade de resíduos, a presença de chorume, o aumento da ocupação do solo (surgimento de bairro, demografia, desmatamento e estação de reciclagem), a ocorrência de queimadas e outras questões indiretamente relacionadas ao local.

\section{Referências}

BARDIN, L. Análise de Conteúdo. Lisboa, Portugal; Ed. 70, LTDA, 2009.

BORTOLOZZI, A; PEREZ FILHO, A. Diagnóstico da educação ambiental no ensino de geografia. Cadernos de Pesquisa, n. 109, p. 145-171, 2000. Disponível em: <http://www.scielo.br/pdf/cp/n109/n109a07.pdf>. Acesso em: 07 jul. 2015.

BRASIL. Lei n 9795/99. Dispõe sobre a educação ambiental. Política Nacional 
de Educação Ambiental. Diário Oficial da União. Brasília, 1999.

BRASIL. Secretaria de Educação Fundamental. Parâmetros curriculares nacionais: Geografia/Secretaria de Educação Fundamental. Brasília: MEC/SEF, 1998.

CALLAI, H. C. Estudar o Lugar para compreender o Mundo. In: Antônio Carlos Castrogiovanni; Helena Copetti Callai; Nestor Andre Karecher (Org.). Ensino de Geografia - práticas e textualizações no cotidiano. 5 ed. Porto Alegre: Mediação, 2006.

CAMPELO JUNIOR, M. V. Educação Ambiental Dialógica: uma proposta de sequência didática com o uso de imagens orbitais. 2015. 88 f. Dissertação (Mestrado Profissional em Ensino de Ciências), Programa de Pós-graduação em Ensino de Ciências, Universidade Federal de Mato Grosso do Sul, Campo Grande - MS, 2015.

CAMPOS, J. A. A.; SANTACANA, M. F.; NEBOT, T. K. Repertorios cognoscitivos de atención, percepción y memoria: documento de trabajo. Barcelona, España: Facultad de Psicología, Universidad de Barcelona, 2008.

CAVALCANTI, L. de S. A Geografia e a realidade escolar contemporânea: avanços, caminhos, alternativas. In: I Seminário Nacional: Currículo em Movimento - Perspectivas Atuais. Belo Horizonte. Anais, 2010.

FERREIRA, D. M.; CUNHA, F. S. S. O software Google Earth aplicado a disciplina de geografia no $1^{\circ}$ ano do ensino médio da escola de ensino fundamental e médio Professor Luis Felipe, Sobral - CE. Revista Homem, Espaço e Tempo, 2010. Disponível em: <http://www.uvanet.br/rhet/artigos_outubro_2010/google_earth.pdf>. Acesso em: 25 set. 2015.

FREIRE, P. Pedagogia do oprimido, 34로. ed. Rio de Janeiro, RJ. Paz e Terra, 2002.

GADOTTI, M. Convite à leitura de Paulo Freire. São Paulo, 1998.

GIL, A. C. Métodos e técnicas de pesquisa social. São Paulo: Atlas. 6. ed. 2008.

GUERRA, A. F. S. As tecnologias educacionais na formação em Educação Ambiental para a sustentabilidade. Rev. Diálogo Educ., Curitiba, v. 10, n. 31, p. 561-579, 2010.

GUIMARÃES, M. Sustentabilidade e Educação Ambiental. In: Cunha, S. B. da; GUERRA, A. J. T.; (org.) A Questão ambiental: diferentes abordagens. 5. ed. Rio de Janeiro: Bertrand Brasil, 2011. p. 81-103.

LEFF, E. Epistemologia Ambiental. São Paulo: Cortez, 2006.

LIBÂNEO, J. C. Didática. São Paulo: Cortez Editora, 1994.

LOUREIRO, C. F. B. Trajetórias e fundamentos da educação ambiental. São Paulo: Cortez, 2012.

MORAN, J. M.; MASETTO, M. T.; BEHRENS, M. A. Novas tecnologias e mediação pedagógica. Campinas: Papirus, 2000. 
PONTUSCHKA, N. N.; PAGANELLI, T. I.; CACETE, N. H. Para ensinar e aprender geografia. 3. ed. São Paulo: Cortez, 2009. 383 p.

SANTOS, M. A Natureza do Espaço: técnica e tempo, razão e emoção. São Paulo: EDUSP, 2002.

SANTOS, M. Metamorfose do espaço habitado. São Paulo: Edusp, 6 $6^{\underline{a}}$ ed, 2 $2^{\underline{a}}$ reimp. 2014.

SILVA FILHO, I. O uso de imagens de satélite no ensino de Geografia: possibilidades e limitações no ensino básico. Dissertação (Mestrado do Programa de estudos pós-graduados em Geografia). PUC- SP, 2008.

SOUZA, D. C. et al. A inserção da educação ambiental nos currículos escolares: análise inicial do contexto de um processo de formação de professores. In: TONZONI-REIS, M. F.; MAIA, J. S. (org.) Educação Ambiental a várias mãos: educação escolar, currículo e políticas públicas. 1. ed. - Araraquara, SP: Junqueira\&Marin, 2014. p. 70-91.

SIMIELLI, M. E. O mapa como meio de comunicação e a alfabetização cartográfica. In: ALMEIDA, R. D. (Org.). Cartografia escolar. 2. ed. São Paulo: Contexto, 2009. p. 71-93.

TESHE, R. Qualitative research: analysis, tipes and software tools. New York: The Falmers Press. 1990.

ZABALA, A. A prática educativa: como ensinar. Trad. Ernani F. da F. Rosa. Porto Alegre: ArtMed, 1998. 